\title{
Construcción y monitorización del Laboratorio REVen para el estudio del impacto de las ventanas integrando eficiencia energética y calidad ambiental interior
}

\section{Construction and monitoring of the REVen Laboratory for the study of the impact of windows on energy efficiency and Indoor Environmental Quality}



\section{RESUMEN}

El proyecto REVen "Rehabilitación energética de viviendas sociales, aplicando productos innovadores de ventana con marcado CE” (BIA2014-56650-JIN), tiene como objetivo realizar un análisis integral del impacto de la ventana en los aspectos relativos a eficiencia energética y calidad ambiental. Para caracterizar los flujos de energía y las condiciones ambientales internas se ha construido el Laboratorio REVen. Este artículo describe la construcción y la monitorización de este laboratorio analizando los datos de su primer año de funcionamiento. Los resultados permiten afirmar que se logra una mejora significativa del confort térmico obteniendo un ahorro de energía anual del $25 \%$.

Palabras clave: Ventanas, eficiencia energética, calidad ambiental interior, celdas de ensayo en condiciones climáticas reales.

\section{ABSTRACT}

REVen Project: "Energy retrofitting of social housing, using innovative window products satisfying CE marking requirements". (BIA2014-56650-JIN) aims to carry out a comprehensive analysis of window impact on aspects related to energy efficiency and indoor environmental quality. REVen Laboratory has been built to characterize the energy flows and internal environmental conditions. This article describes the construction and monitoring of this laboratory analyzing the data of its first year of operation. Results can affirm that in the conditions of the test, a significant improvement on thermal comfort is observed obtaining an annual energy saving of $25 \%$.

Keywords: Windows, energy efficiency, indoor environmental quality, test cells under real climatic conditions.

(*) Dra. Arquitecta. E.T.S. de Arquitectura, Universidad Politécnica de Madrid (UPM), Madrid (Spain)

${ }^{(*)}$ Dr. Arquitecto. Científico titular. Instituto de Ciencias de la Construcción Eduardo Torrroja (CSIC), Madrid (Spain)

${ }^{(* *)}$ Ingeniera. Universidad Politécnica de Madrid (UPM), Madrid (Spain)

${ }^{\left.{ }^{* * * *}\right)}$ Dr. Ingeniero de Telecomunicación. E.T.S. Ingenieros de Telecomunicación, UPM, Madrid (Spain)

Persona de contacto/Corresponding author: beatriz.arranz@upm.es (B. Arranz)

ORCID: https://orcid.org/oooo-0002-6675-0248 (B. Arranz); https://orcid.org/oooo-0oo2-7815-3109 (I. Oteiza); https://orcid.org/oooo-00o2-6912-4357 (E. Delgado); https://orcid.org/oooo-0oo1-8926-5328 (A. Gutiérrez)

Cómo citar este artículo/Citation: Arranz, B.; Oteiza, I.; Delgado, E.; Gutierrez, A. (2020). Construcción y monitorización del Laboratorio REVen para el estudio del impacto de las ventanas integrando eficiencia energética y calidad ambiental interior. Informes de la Construcción, 72(557): e324. https://doi.org/10.3989/ic.67523

Copyright: ( $) 2020$ CSIC. Este es un artículo de acceso abierto distribuido bajo los términos de la licencia de uso y distribución Creative Commons Reconocimiento 4.0 Internacional (CC BY 4.0). 


\section{INTRODUCCIÓN}

Con el objetivo de reducir el consumo de energía y las emisiones de $\mathrm{CO} 2$ la normativa relativa a la eficiencia energética de los edificios (1) establece que para el año 2020 todos los edificios nuevos deben ser edificios de consumo casi nulo. Sin embargo, en la mayoría de los países europeos el ratio de crecimiento anual del parque de viviendas se sitúa en 1-1,5\% (2). Se estima que en torno al $80 \%$ del stock actual estará en uso en 2030 y al menos el $30 \%$ continuará ocupado durante décadas (3).

En España las características de las viviendas construidas varían en función de la fecha y el lugar de construcción, pero tienen en común su gran potencial de mejora. La normativa relativa a la eficiencia energética de los edificios para los edificios existentes, considera que la inversión más eficiente, en lo que respecta a las mejoras logradas, se alcanza al realizar grandes rehabilitaciones del edificio o de las partes con una mayor repercusión en su consumo energético (2).

En este sentido, las ventanas se pueden considerar como elementos con gran incidencia en el consumo y, por tanto, con un gran potencial de ahorro energético asociado. En España, entre el $25 \%$ y el $30 \%$ de nuestras necesidades de calefacción se deben a las pérdidas de calor que se producen a través de las ventanas (4).

Pero el único indicador a considerar no debe ser la eficiencia energética, en 2010 el 10\% de los hogares en España se encontraba en situación de pobreza energética (5). Además de encontrarse en una situación de ausencia de confort térmico, existen serias consecuencias para la salud derivadas de vivir en una casa con una temperatura inadecuada. Por tanto, existe un porcentaje de usuarios para quienes la actuación en la envolvente de su vivienda repercutirá en una mejora en sus condiciones de vida, sin necesariamente ver esta mejora reflejada en su consumo.

Actualmente, el sector de la edificación cuenta con tres grandes problemas: el alto consumo energético, el cambio climático local y la pobreza energética. Los tres temas están fuertemente interrelacionados presentando significativas sinergias (6). La Comisión Europea ha incluido la pobreza energética en sus políticas de energía y protección al consumidor. Las directrices del mercado interior relativas al consumo eléctrico y de gas obligan a los Estados Miembros a desarrollar planes de trabajo para abordar esta cuestión $(7,8)$. Conseguir en los edificios confort higrotérmico será, por tanto, uno de los objetivos establecidos por la Comisión Europea, tan necesario como lograr un uso eficiente de la energía.

Los principales aspectos a considerar para asegurar la calidad ambiental interior en un edificio son el confort higrotérmico, el confort acústico, el confort lumínico, así como la calidad de aire (9). Las ventanas intervienen en todos estos aspectos, influyendo en gran medida en el confort y la salud de las personas que habitamos los espacios.

La historia de la arquitectura está relacionada con la evolución de la fachada, especialmente los criterios de comodidad e higiene. La necesidad de proporcionar efectiva y racionalmente iluminación y ventilación natural sitúa a la ventana como uno de los componentes de fachada clave en el bienestar psicosomático de los ocupantes de las construcciones $(10,11)$.
El Proyecto REVen analiza soluciones para rehabilitación de la vivienda social en España entre 1940-1980, anteriores al Código Técnico de la edificación en las que la renovación de aire se daba exclusivamente por la ventana. En la actualidad, desde el año 2006, en Código técnico de la Edificación (HS3) define las condiciones que deben cumplir los edificios de vivienda para garantizar una óptima calidad de aire de forma independiente a la apertura de las ventanas.

$\mathrm{Al}$ modificar los elementos esenciales de la ventana para mejorar su eficiencia energética podemos influir de forma perjudicial en algunos de sus beneficios. La determinación de la solución de ventana óptima para cada situación específica implicará un enfoque general, analizando la compatibilidad entre la eficiencia energética y la calidad ambiental interior. No considerar todos los aspectos de forma integrada y holística inevitablemente resultará en un consumo energético más alto y en discrepancias sociales (6).

Por lo tanto, cualquier tipo de rehabilitación debería basarse en un conocimiento exhaustivo del stock residencial. El proyecto REVen tiene como objetivo realizar un análisis integral de los aspectos relativos a eficiencia energética y calidad ambiental interior que intervienen en la ventana.

\section{METODOLOGÍA}

En la selección de sistemas acristalados es importante lograr una solución de compromiso, que no será la óptima en verano o en invierno, pero sí durante el ciclo anual. Dando una respuesta equilibrada a todos los flujos de energía que ocurren a través de este elemento constructivo y a los requisitos de confort interior asociados.

Para caracterizar los flujos de energía y las condiciones ambientales internas de elementos de fachada, se ha construido el Laboratorio REVen (laboratorio al aire libre en condiciones climáticas reales), donde se pueden monitorizar diferentes soluciones, permitiendo discriminar variables y estimar su impacto en la demanda de energía y la calidad ambiental interior.

El uso de celdas de ensayo está extendido en el campo de la investigación dedicado a la evaluación de componentes de fachada, existiendo numerosas instalaciones en universidades y organismos de investigación. Distintas publicaciones recogen información sobre algunas de estas celdas de ensayo y el progreso en esta área en los últimos años en Europa comparando estas instalaciones $(12,13)$. En el proyecto PASSYS (PASsive Solar Components and SYStems Testing) se construyeron en los años 80 numerosas celdas en distintas localizaciones, el proyecto PASSYS consistió en diseñar un procedimiento estandarizado para la caracterización de componentes constructivos usados en la edificación. Durante el desarrollo del proyecto PASSYS se llegó a la conclusión que las células PASSYS y el método de análisis de datos era muy lento y costoso. El proyecto PASLINK tuvo como objetivo modificar las células de ensayo PASSYS de forma que el tiempo de los ensayos disminuyera y la calidad de los resultados fuera mejor (14).

En otras localizaciones se encuentran también interesantes celdas de ensayo, en Estados Unidos cabe destacar las instalaciones del Laboratorio de Berkeley destinadas específicamente al estudio de ventanas "Advance Windows Testbed Facility" y "Mobile Windows Thermal Test (MoWiTT) Facility" 
la primera se centra en fachadas dinámicas inteligentes y sistemas de iluminación y la segunda, de carácter móvil, analiza vidrios con alto aislamiento (15). En clima tropical, podemos encontrar en Santo Domingo (República Dominicana) dos celdas de ensayo destinadas a la validación del comportamiento térmico y lumínico en clima tropical (16). En España en las distintas zonas climáticas existen también varias instalaciones. Cabe destacar, en Madrid, en clima continental el Laboratorio GESLAB de la UPM, que cuenta con 11 celdas de ensayo para el estudio de componentes de fachada y cubierta (17); en Sevilla en clima mediterráneo la Universidad de Sevilla analiza en dos pares de celdas componentes de fachada para rehabilitación (18), en la Plataforma Solar de Almería (PSA) en clima desértico se prueban distintos componentes de fachada en diversas instalaciones (19) y en Álava, en clima de baja radiación solar, en dos celdas PASLINK se analizan componentes tanto de fachada y como de cubierta (20).

Este artículo describe el trabajo realizado en las celdas de ensayo, denominadas "Laboratorio REVen", su construcción, su monitorización, analizando los datos de su primer año de funcionamiento. Se trata de una instalación diseñada en el ámbito del Proyecto REVen, estos datos se contrastarán posteriormente con otros obtenidos en una vivienda, donde intervine el usuario y en simulaciones. Las celdas de ensayo no deben considerarse como un fin en sí mismas sino como un paso en el análisis, que se complementará en la fase de validación y el uso posterior se simulaciones energéticas (21, 22, 23, 24).

\subsection{Descripción del Laboratorio REVen}

El Laboratorio REVen (Figura 1) se encuentra situado en las instalaciones del Instituto Eduardo Torroja de Ciencias de la Construcción (IETcc-CSIC) en Arganda del Rey (Figura 2). Arganda del Rey está situada en el sureste de la Comunidad de Madrid, a 25 kilómetros de Madrid capital, cuenta con amplias zonas verdes, su clima es mediterráneo continental
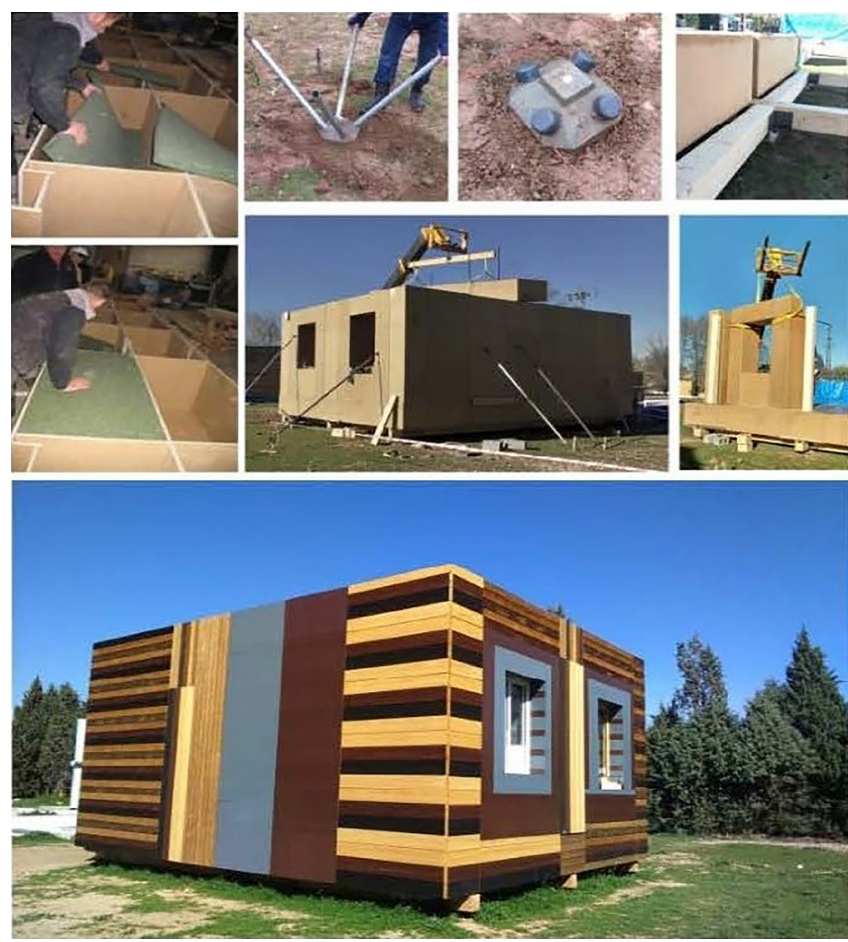

Figura 1. Imagen del Laboratorio REVen -IETcc-CSIC. Fotografías de las diferentes etapas de construcción.



Figura 2. Localización en las instalaciones del IETcc en Arganda del Rey. (Imagen aérea de Google Maps).

similar al clima mediterráneo en el régimen de precipitaciones, pero con características de climas continentales en cuanto a las temperaturas, que son más extremas. Los veranos son bastante cálidos y los inviernos bastante fríos con una oscilación de $18,5^{\circ} \mathrm{C}$. La estación estival es la más seca y se superan con gran frecuencia los $30^{\circ} \mathrm{C}$, alcanzándose esporádicamente más de $35^{\circ} \mathrm{C}$. En invierno es frecuente que las temperaturas bajen de los $\mathrm{O}^{\circ} \mathrm{C}$, produciéndose numerosas heladas en las noches despejadas de nubes y nevadas esporádicas.

El laboratorio REVen consta de dos celdas de ensayo orientadas a Sur con un área de servicio en la zona Norte, ha sido construido con madera, ya que, dadas las características del proyecto se pretende que su impacto ambiental sea el menor posible, además de avanzar en el conocimiento de la construcción de edificios industrializados con este material. Se construye mediante un sistema industrializado de paneles 2D (Figura 2) que consta de $60 \mathrm{~cm}$ de aislamiento de algodón reciclado de GEOPANNEL, alojados entre dos tableros de madera SUPERPAN P 5 de FINSA de $18 \mathrm{~mm}$, en el exterior lleva una barrera de vapor de DUPOND y una fachada ventilada de madera de STORENSO.

La cubierta, fachadas y el suelo llevan los mismos elementos, además la cubierta se cubre con pintura impermeabilizante de DANOSA. La envolvente consta de paneles construidos en taller por TAUJEL, en obra se monta una estructura de madera laminada sobre la cimentación también industrializada de PILOEDRE, sobre esta estructura se montan in situ los paneles, la barrera de vapor, la impermeabilización y la fachada ventilada (Figura 3).

Las fachadas Este, Oeste y Sur están compuestas por paneles que se pueden desmontar para probar distintos componentes de fachada en estas orientaciones en fututos trabajos dotando al Laboratorio de gran versatilidad.

La envolvente de alto aislamiento, "cuasi adiabática”, tiene $64 \mathrm{~cm}$ de espesor con una transmitancia térmica de $0,055 \mathrm{~W} /$ $\mathrm{m} 2 \mathrm{~K}$ (tabla 1). 

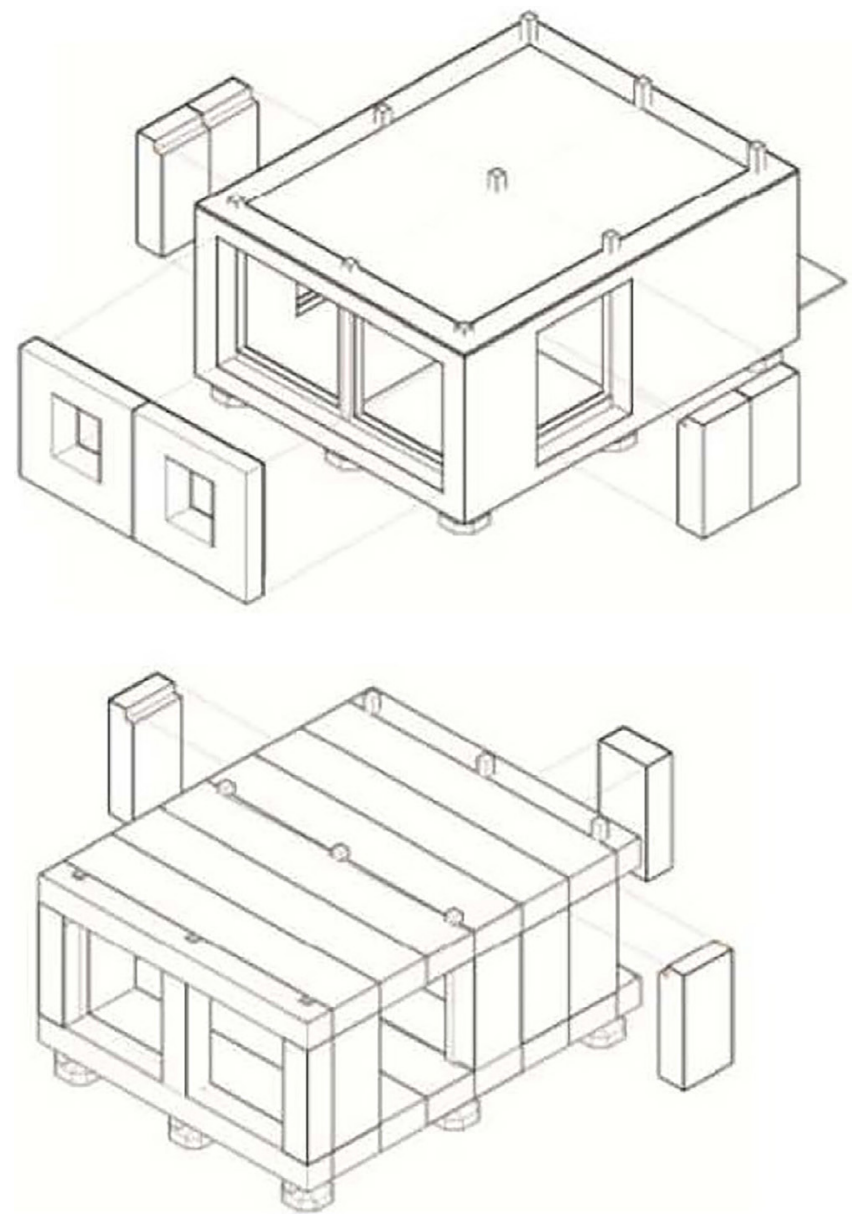

Figura 3. Sistema de construcción industrializado mediante paneles $2 \mathrm{D}$.

Tabla 1. Características térmicas de la envolvente.

\begin{tabular}{|l|c|c|c|}
\hline \multicolumn{1}{|c|}{ ENVOLVENTE } & $\begin{array}{c}\text { Conductividad } \\
\lambda(\mathbf{W} / \mathbf{m K})\end{array}$ & $\begin{array}{c}\text { Espesor } \\
\mathbf{e}(\mathbf{m})\end{array}$ & $\begin{array}{c}\text { Resistencia } \\
\mathbf{R}=\mathbf{e} / \boldsymbol{\lambda} \\
\left(\mathbf{m}^{\mathbf{2}} \mathbf{K} / \mathbf{W}\right)\end{array}$ \\
\hline Capa aire exterior & - & - & 0,040 \\
\hline Superpan P5 & 0,130 & 0,018 & 0,170 \\
\hline geopannel classic & 0,034 & 0,600 & 17,647 \\
\hline Superpan P5 & 0,130 & 0,018 & 0,138 \\
\hline Barrera de vapor & & & \\
\hline Capa aire interior & - & - & 0,130 \\
\hline & Rtotal & 18,126 & \\
\hline $\mathrm{U}=0,0552 \mathrm{~W} / \mathrm{m}^{2} \mathrm{k}$ & E total $=$ & 0,64 & \\
\hline
\end{tabular}

Las dimensiones de cada celda son 2,68 m de ancho por 5,60 m de largo. (Figura 4).

\subsection{Ensayo}

El ensayo efectuado en el primer año de trabajo ha consistido en la comparativa de dos ventanas, midiendo su consumo y otros parámetros de Calidad Ambiental Interior.

Selección de las muestras experimentadas:

La selección de la muestra de referencia se basa en la caracterización del parque de viviendas (23), en la que se observa

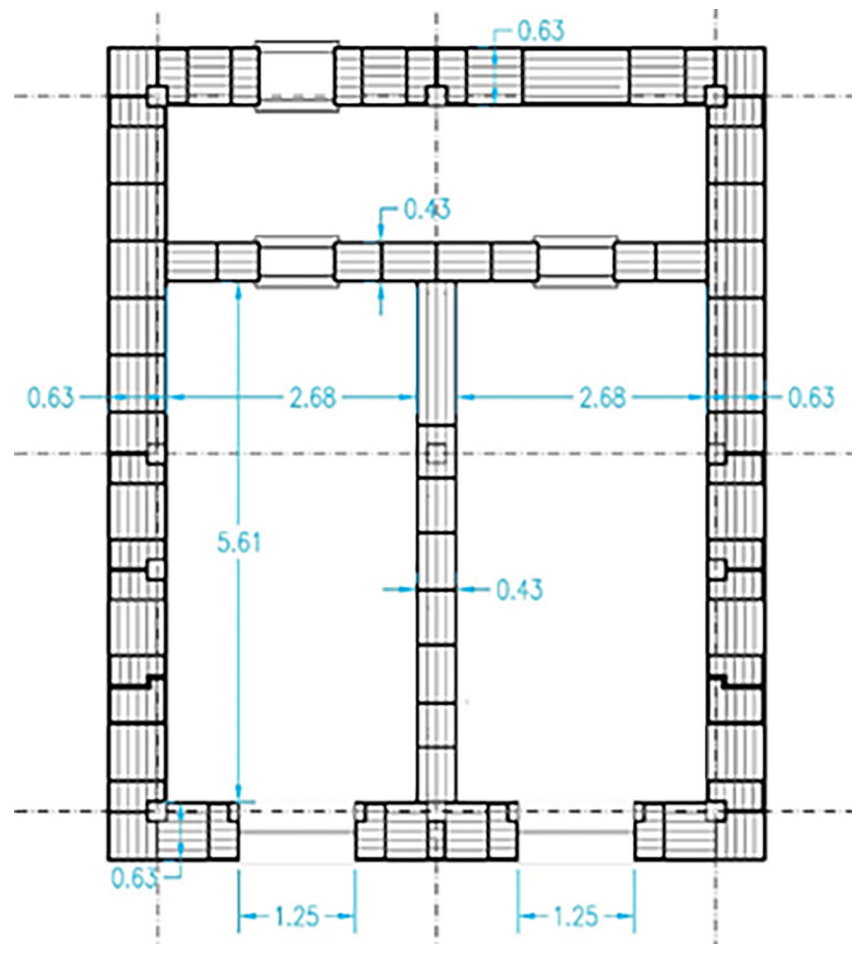

Figura 4. Planta del Laboratorio REVen.

que debido al III Plan Nacional de Vivienda (1961-76), existe un gran número de edificios de vivienda social de este periodo que necesita ser rehabilitado, ya que presentan por lo general pobre calidad constructiva.

La muestra optimizada se selecciona en base a simulaciones, estudios y cálculos teóricos, atendiendo a criterios de eficiencia energética, de transmitancia lumínica y de calidad de aire.

Por lo tanto, se compara una ventana de referencia, cuyas características corresponden con las del periodo 1961-76 con una ventana con características mejoradas.

La ventana de referencia (Tabla 2) es una ventana tradicional, de aluminio (sin rotura de puente térmico), con acristalamiento simple claro de $4 \mathrm{~mm}$, una solución con las características de las ventanas que se colocaban en el periodo 1961-76. La ventana optimizada (Tabla 2) incorpora un marco de madera (CARPINTEK) y acristalamiento con gas argón, control solar y bajo emisivo (SAINT GOBAIN). La ventilación en la ventana de referencia se realiza por medio de la apertura del 50\% del área de la ventana todas las mañanas a las 9:00 durante 15 minutos, la apertura se automatiza simulando la ventilación manual que realizamos en las viviendas del pe-

Tabla 2. Características de las muestras seleccionadas.

\begin{tabular}{|l|l|l|l|c|c|c|}
\hline & MARCO & VIDRIO & $\begin{array}{l}\text { RENOVACIÓN } \\
\text { DE AIRE }\end{array}$ & U & SHGC & VT \\
\hline R & Aluminio & $\begin{array}{l}\text { Vidrio } \\
4 \mathrm{~mm}\end{array}$ & $\begin{array}{l}\text { Apertura/cierre } \\
\text { automatico }\end{array}$ & 5,4 & 0,73 & 0,71 \\
\hline O & $\begin{array}{l}\text { Madera } \\
\text { LighTEK } \\
68\end{array}$ & $\begin{array}{l}\text { Planitherm } \\
\text { XN F2 } \\
4(16 \\
\text { argon)4. }\end{array}$ & $\begin{array}{l}\text { PremiVent } \\
\text { Recuperación } \\
\text { de calor. } \\
\text { Ventilación } \\
\text { mecánica. }\end{array}$ & 1,88 & 0,33 & 0,50 \\
\hline R & Ventana de Referencia \\
\hline O & Ventana Optimizada \\
\hline
\end{tabular}


riodo 1961-76. La ventana optimizada integra un innovador intercambiador de calor diseñado específicamente para ventanas PremiVent (ZEHNDER) (Tabla 2). El intercambiador de calor sigue los principios de intercambio de calor por placas, se coloca en el muro, sin necesidad de instalar conductos, recuperando el calor (o frío) del aire de salida, templando el aire que entra, reduciendo las pérdidas de calor por renovación de aire. Las muestras a comparar son de 1,5 m de altura por 1,25 $\mathrm{m}$ de ancho (Figura 5).

Ambos espacios constan de una bomba de calor independiente modelo VAILLANT VAI 6 de $2.5 \mathrm{~kW}$, de clase energética A, que cumplen con los requisitos de la Directiva ErP 2014, con un SEER/SCOP de 4.6/3.8.

\subsection{Monitorización}

El objeto de monitorización consiste en adquirir las medidas necesarias de parámetros de calidad ambiental interior y consumo de energía eléctrica para realizar la evaluación comparativa de las dos ventanas. Por lo tanto, se implanta un sistema de monitorización, con capacidades de control, en las dos celdas de ensayo. El sistema implantado es modular y escalable para poder tener versatilidad en futuros proyectos, se instala una estructura que consta de un sistema central donde se añaden módulos para adquirir las medidas de los diferentes sensores y un módulo de actuación para mover el motor que abre y cierra la ventana.

En cada uno de los espacios se miden las mide las siguientes variables (Figura 6):

- 6 medidas de temperatura superficial, tres interiores y tres exteriores, en el vidrio en cada una de las ventanas mediante termopares (RTi 1,2,3; RTe 1,2,3; OTi 1,2,3; OTe 1,2,3). (Figura 6, figura 11, figura 12).

- 1 medida de humedad relativa en el centro del espacio en el plano de trabajo a $70 \mathrm{~cm}$ de altura del suelo. (Figura 6).

- 1 medida de calidad del aire (CO2) en el centro del espacio en el plano de trabajo a $70 \mathrm{~cm}$ de altura del suelo. (Figura 6).

- 1 medida de temperatura interior en el centro del espacio en el plano de trabajo a $70 \mathrm{~cm}$ de altura del suelo. (Figura 6).

- 3 medidas de iluminación a la altura del plano de trabajo a $70 \mathrm{~cm}$ de altura del suelo. (Figura 6).

- 1 medida de consumo eléctrico de una bomba de calor.

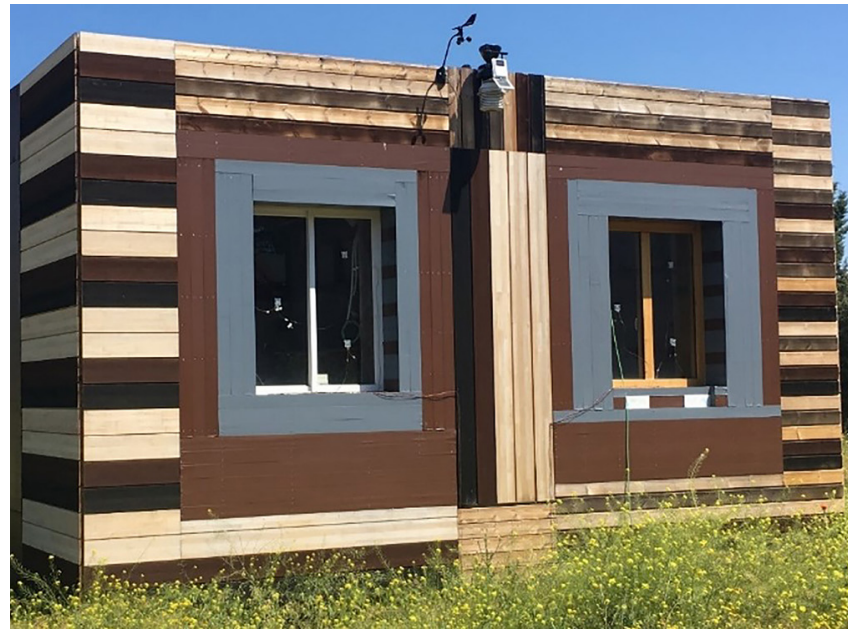

Figura 5. Fachada Sur del Laboratorio REVen. A la izquierda ventana de referencia, a derecha ventana optimizada.
Todos los sensores son alámbricos y cableados por techos, suelos y paredes hasta su distribución al panel de monitorización (Figura 7). El Panel de monitorización es el encargado

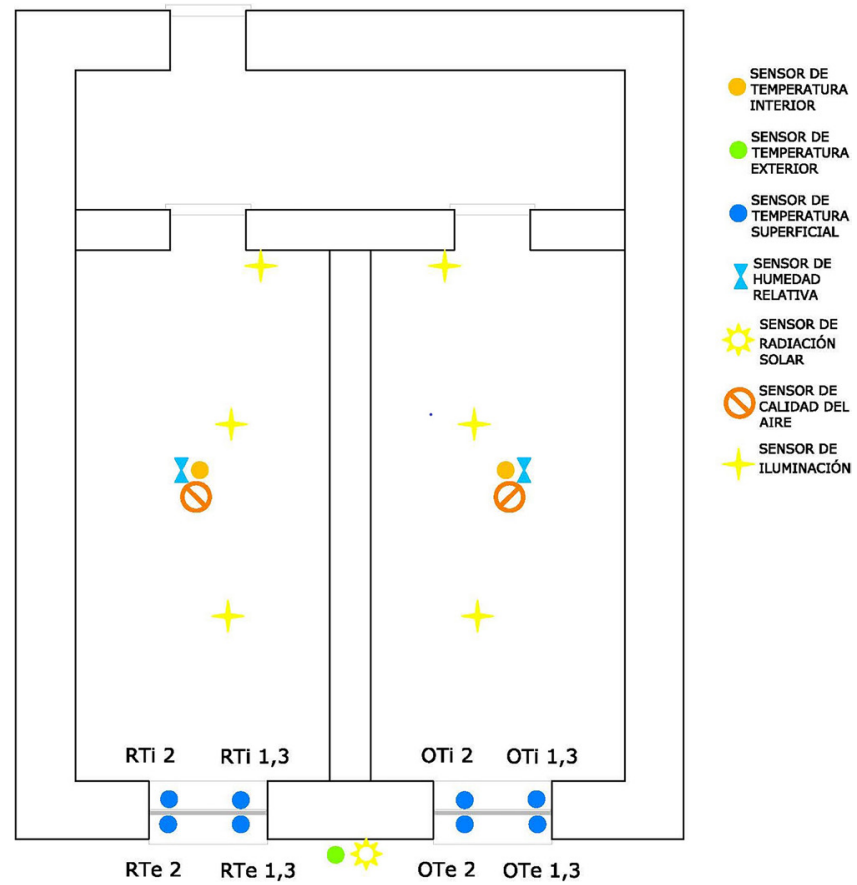

Figura 6. Planta de monitorización. Ubicación de los sensores.
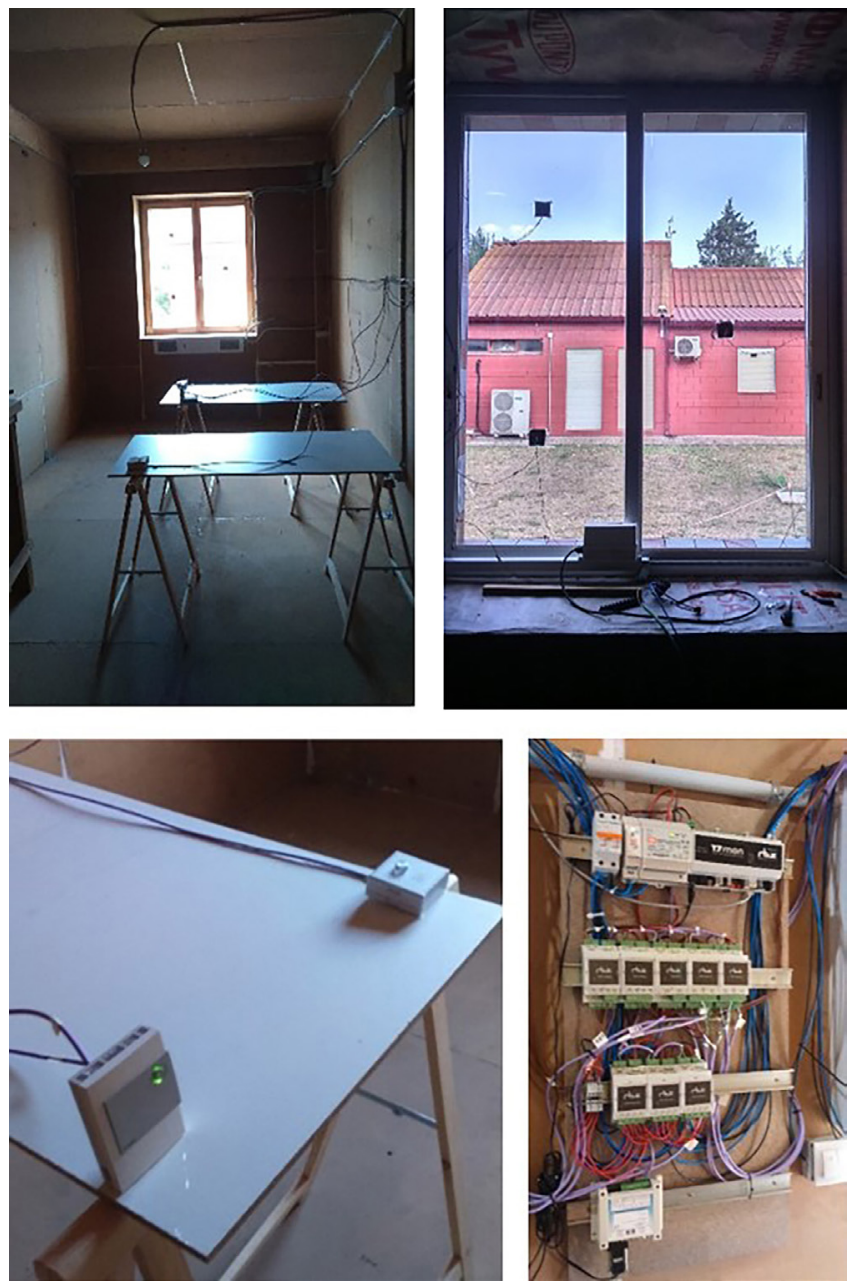

Figura 7. Sensores en interior de celdas y Panel de monitorización. 
de obtener la información de todos y cada uno de los sensores, almacenar la información de los sensores a una frecuencia de 10 minutos y enviarlos a un servidor de datos para su posterior procesado. En el exterior en fachada sur se instala una estación meteorológica (DAVIS VANTAGE PRO2) (ver Figura 8).

El panel de monitorización recibe la información de los sensores, consta de los siguientes elementos:

- Sistema Empotrado (TJMon): Dicho sistema es el encargado de comunicarse con las diferentes tarjetas de adquisición de datos, obtener la información necesaria, almacenarla localmente y enviarla a los servidores donde se procesan los datos.

- Módulo de adquisición de termopares (SDIN-THERM): Un sistema de adquisición capaz de adquirir hasta ocho medi-

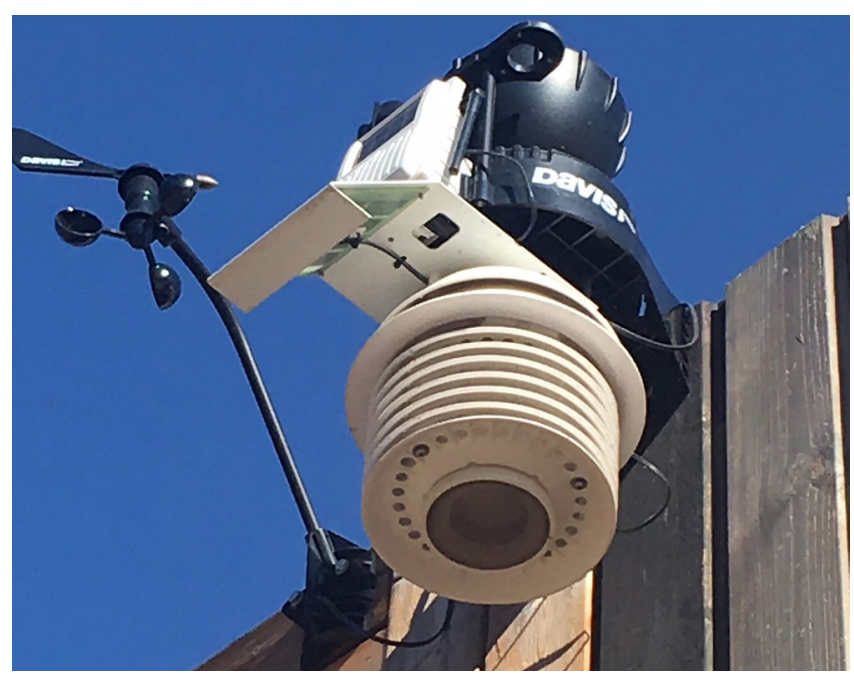

Figura 8. Estación meteorológica en fachada Sur. das de termopares, es el encargado de obtener las medidas de temperatura superficial de los módulos.

- Módulo de adquisición de NTCs (SDIN-NTC): Un sistema de adquisición capaz de adquirir hasta cuatro medidas de sensores NTC, PTC, PT10o o PT100o, es el encargado de obtener las medidas de temperatura ambiente de los módulos, un NTC 1.8K.

- Módulo de adquisición de señales analógicas (SDIN-ANALOG): Un sistema de adquisición capaz de adquirir hasta seis medidas de sensores con salidas en 4-20mA o o-10V., encargado de obtener las medidas de humedad, $\mathrm{CO} 2$ e iluminación.

- Contador eléctrico: Un analizador de red, encargado de obtener las medidas de consumo de una bomba de calor.

Además, se han incorporado dos módulos de actuación:

- Módulo de actuación AC (SDIN-AC-Out), con capacidad de controlar hasta cuatro salidas en corriente alterna $220 \mathrm{~V}$ hasta un máximo de 16 amperios.

- Módulo de actuación DC (SDIN-DC-Out), con capacidad de controlar hasta 4 salidas en corriente contónua, hasta un máximo de 10 amperios.

Por último, se incorpora un módulo de comunicación con la estación meteorológica, que la información recibida de manera inalámbrica por la consola de control, a un bus RS-485 que se comunica con el TJMon.

\subsection{Disponibilidad de datos procesados en tiempo real}

Se ha creado una interfaz web de monitorización para facilitar el acceso a los datos obtenidos (Figura 9) y procesados, este acceso se facilita al público general a través de la página web del proyecto (Figura 10).

\section{Home Monitoring}
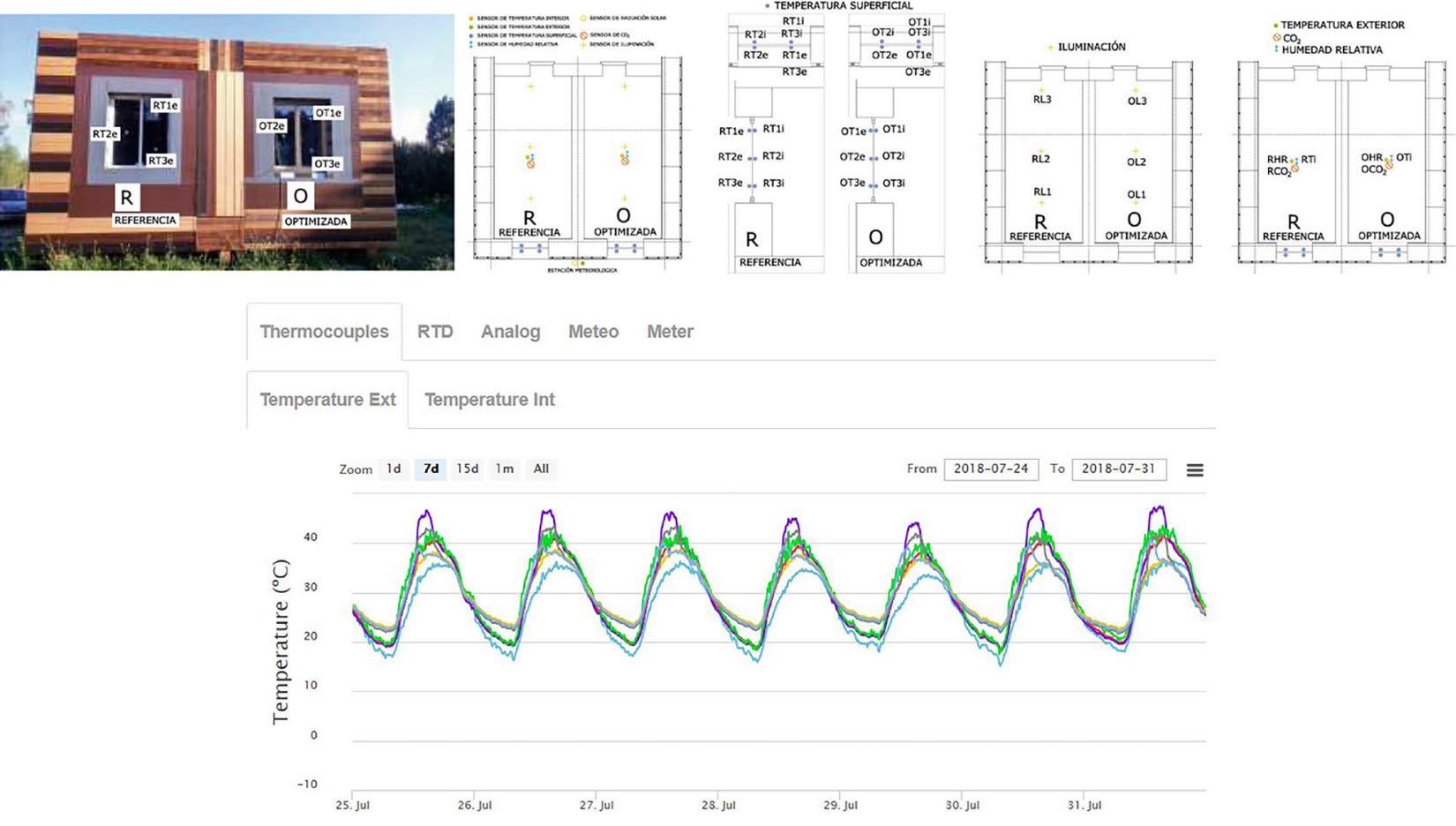

Figura 9. Interfaz web de acceso a los datos obtenidos. 


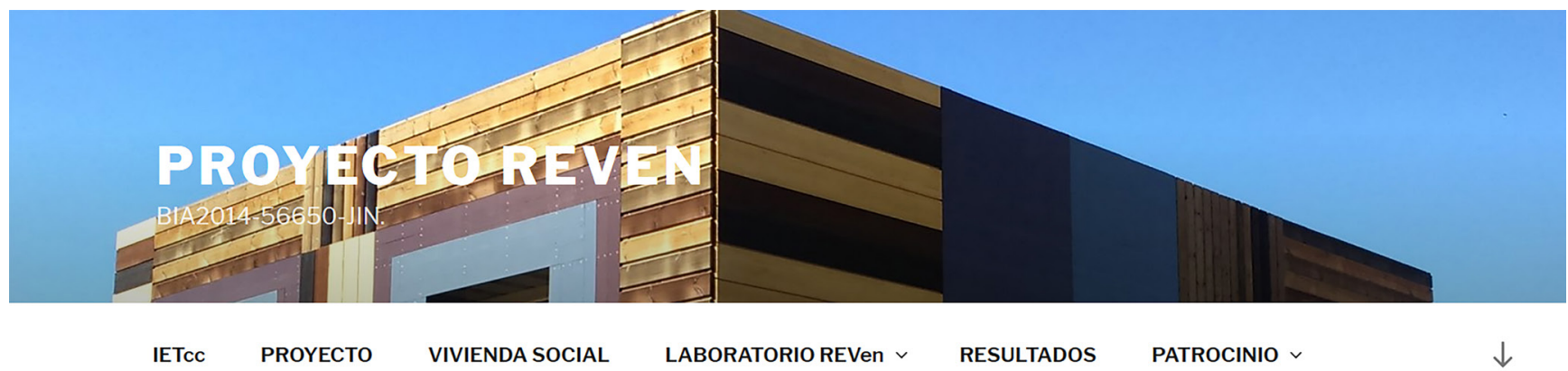

\section{ENTRADAS}

22 ENERO, 2018

Datos Laboratorio REVen

ENTRADAS RECIENTES

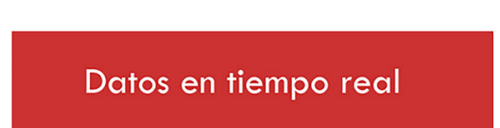

Datos Laboratorio REVen

Figura 10. Página de inicio de la web del proyecto REVen. http://proyectoreven.ietcc.csic.es/

Además de los datos procesados que se muestran en la página web, los investigadores tienen acceso a los datos instantáneos obtenidos por el sistema de monitorización.

\section{RESULTADOS Y DISCUSIÓN}

En esta sección se describen y analizan los resultados obtenidos de la monitorización.

El periodo de monitorización comprende 14 meses, abarcando del 01/07/2017 hasta el 31/o8/2018 registrando los parámetros de calidad ambiental interior, temperatura superficial de los acristalamientos y consumo de energía. Observándose diferencias entre las dos celdas durante todo el periodo de monitorización.

En cuanto a los resultados de temperatura superficial de los acristalamientos en las figuras 11 y 12 se marca la posición de los sensores en el exterior de las dos ventanas, en la cara interior del acristalamiento hay otros 3 sensores en cada ventana que coinciden en la misma posición con los exteriores.

Se recogen a continuación en detalle los datos de un día de verano con alta radiación solar (01/08/2017).

En las Figuras 13 y 14 se observa la temperatura superficial interior y exterior de los acristalamientos. En la ventana optimizada se observan incrementos de temperatura superficial entre interior y exterior máximos de $10^{\circ} \mathrm{C}$ durante el día y de en torno a $4{ }^{\circ} \mathrm{C}$ en la madrugada cuando la temperatura desciende por debajo de $25^{\circ} \mathrm{C}$ (Figura 13). Esto pone de manifiesto el efecto del aislamiento evitando el flujo directo de energía de una cara a la otra del acristalamiento. Sin embargo, en la ventana de referencia estos incrementos son inapreciables, observándose un flujo continuo de energía entre las dos caras del acristalamiento (Figura 14).

Realizando el promedio de los tres termopares colocados en cada una de las caras (Figura 15) se aprecia como en la ventana optimizada (línea en color verde) la cara interior se mantie-

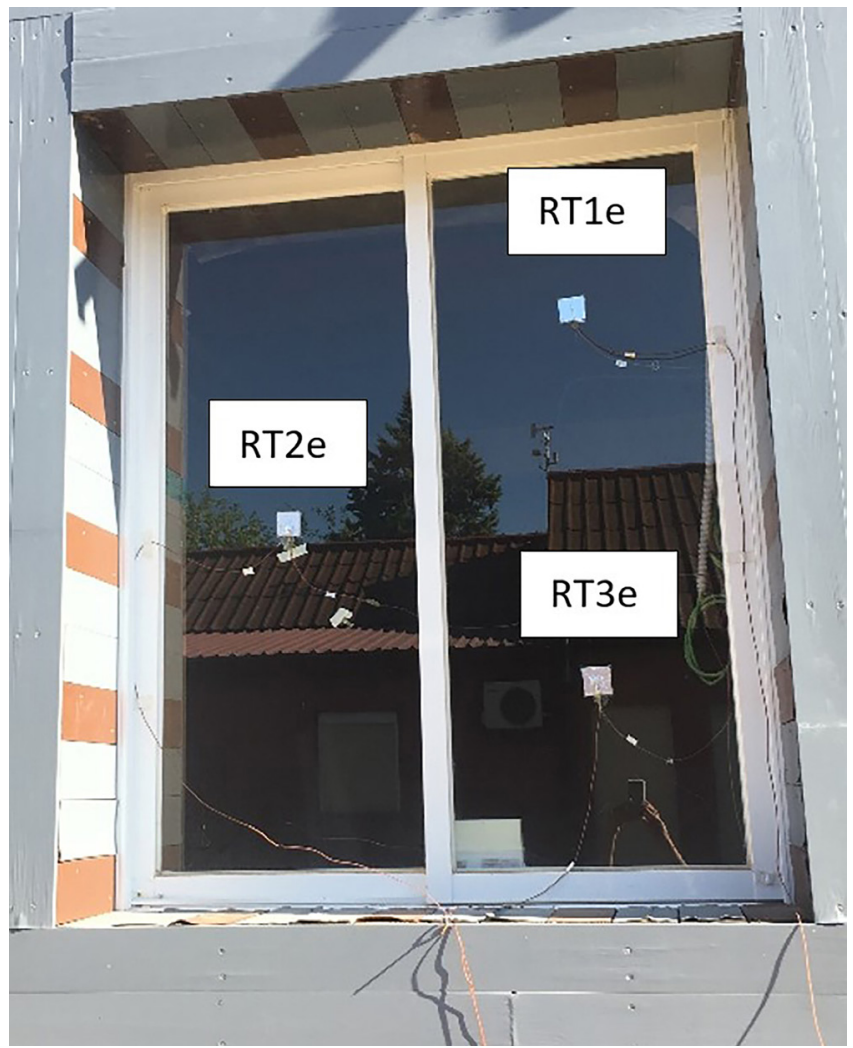

Figura 11. Posición de los termopares en los acristalamientos. Ventana de Referencia.

ne más baja y próxima a la temperatura de confort en verano $\left(17^{\circ} \mathrm{C}-26^{\circ} \mathrm{C}\right.$ ) que en el caso de la ventana de referencia (en color rojo) impidiendo la transferencia de calor a cara al exterior.

En este promedio en la ventana de referencia se observan incrementos de temperatura del orden de $10^{\circ} \mathrm{C}$ entre las 13:00 y las 20:00 horas invirtiendo el sentido del flujo de calor en la madrugada en los momentos más frescos observándose incrementos de en torno a $4^{\circ} \mathrm{C}$, mientras que en la ventana de 


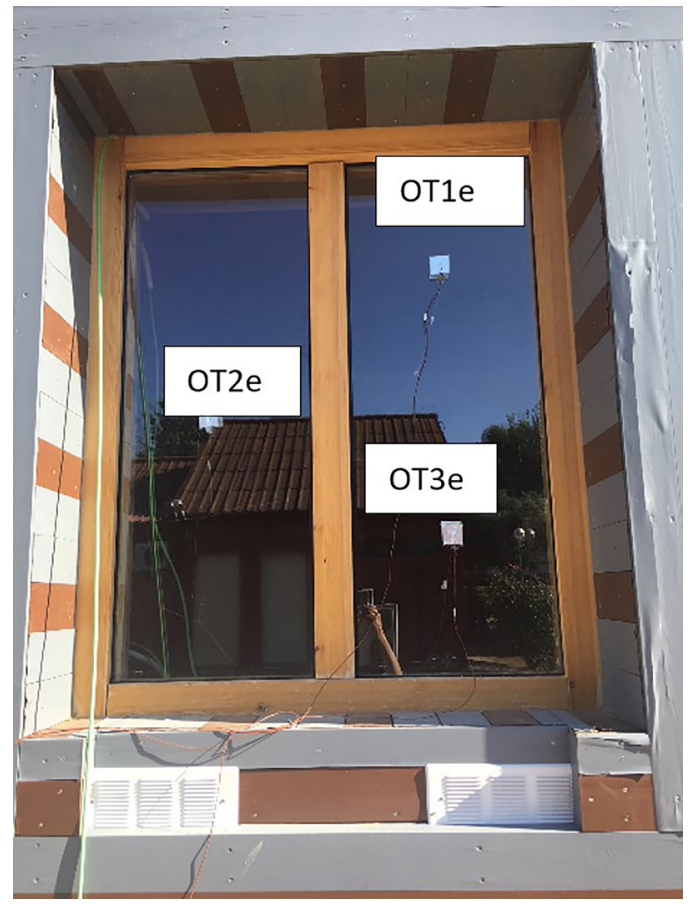

Figura 12. Posición de los termopares en los acristalamientos. Ventana Optimizada.

Temperatura superficial ventana Optimizada 1/8/2017

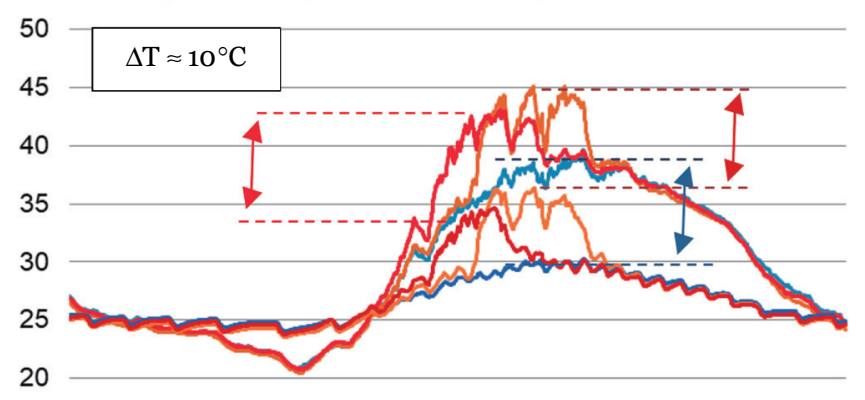

15

ㅇํํ ํํㄴ ○்
- OT1e
- OT2e
- OT3e

Figura 13. Temperatura superficial ventana Optimizada $1 / 8 / 2017$ $\Delta \mathrm{T}$ entre sensores de la cara exterior y la interior.

Temperatura superficial ventana Referencia 1/8/2017



15

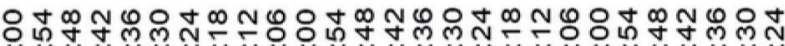
o



Figura 14. Temperatura superficial ventana de Referencia 1/8/2017. referencia temperatura superficial interior y exterior prácticamente coinciden.

Estos datos reflejan en primera instancia el derroche de energía que se produce en la celda con la ventana de referencia en la que la ventana no ejerce ninguna resistencia al paso del calor o del frío. Pero además la temperatura superficial de la ventana de referencia fluctúa y se aleja de la temperatura de confort, lo que va a producir una falta de confort térmico a los usuarios de ese espacio que estén próximos a la ventana. Estos usuarios percibirán calor porque la superficie acristalada irradiará calor hacia ellos o frío porque ellos irradiaran calor a la superficie fría. En ambos casos se producirá falta de confort por asimetría térmica. En el caso de la ventana optimizada este fenómeno se matiza ya que la temperatura fluctúa menos y está más próxima a la temperatura de confort.

En relación a las temperaturas del aire interior en cada celda (Figura 16) se comprueba que se mantienen en el rango de confort, observándose una diferencia poco significativa, de entre 1 y $0,5^{\circ} \mathrm{C}$, entre ellas, la celda de la ventana optimizada siempre está a menor temperatura, la temperatura de consigna fijada para la bomba de calor para refrigeración es de $25^{\circ} \mathrm{C}$ en ambos casos.

Temperatura superficial promedio del vidrio 1/8/2017

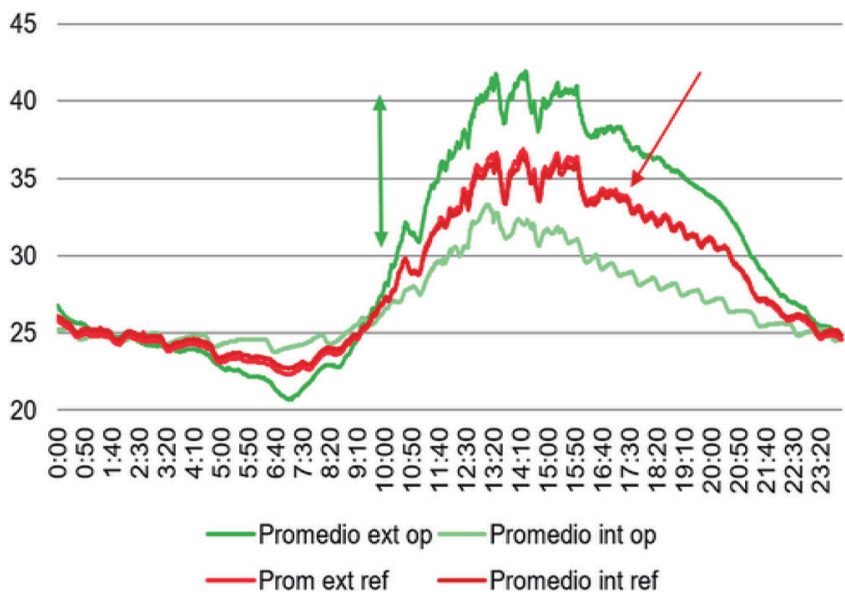

Figura 15. Temperatura superficial promedio de ventana de referencia y ventana optimizada. 1/8/2017.

\section{Temperatura interior}

30

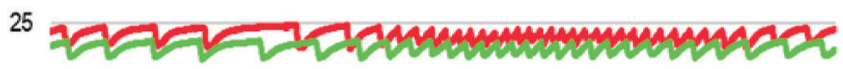

20

15

10

5

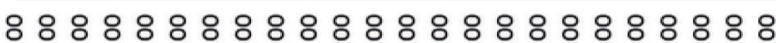

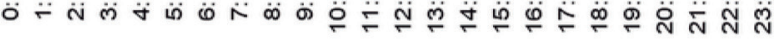

Tint REF Tint OPT

Figura 16. Temperatura interior de las dos celdas de ensayo. $1 / 8 / 2017$. 
A continuación, podemos observar en detalle los consumos de las dos celdas el mes de agosto de 2017, el consumo destinado a refrigeración en la celda con la ventana optimizada siempre es inferior al de la ventana de referencia, el consumo acumulado en todo el mes de agosto de la ventana optimizada es un $19 \%$ inferior al de la ventana de referencia (Figura 17).

Analizando los datos anuales se han seleccionado días tipo con alta y baja radiación para verano, otoño e invierno (Tabla 3), pudiéndose observar un resumen de valores significativos como datos de radiación solar y temperatura exterior, las temperaturas superficiales promedio del vidrio, los incrementos de temperatura del vidrio, los consumos y el porcentaje de ahorro en días de alta y baja radiación durante el primer año de medición.

Observamos como en todos los días seleccionados se obtienen ahorros, y la temperatura máxima y mínima interior siempre está más próxima a la temperatura de confort en la ventana optimizada.

A lo largo del año cuando la temperatura exterior se aleja en mayor medida de la de confort interior (Figura 18) es cuando mayores incrementos de temperatura se dan entre las dos caras del vidrio de la ventana Optimizada (verde), lo que indica un comportamiento optimo y menores incrementos de temperatura se dan entre las dos caras del vidrio de la ventana

Consumo mes de Agosto 2017

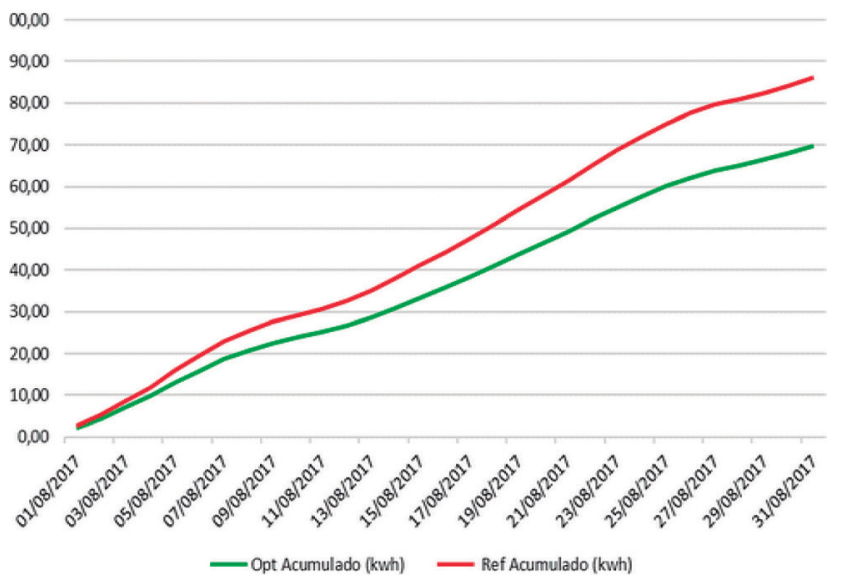

Figura 17. Consumo destinado a refrigeración.

Tabla 3. Resumen de valores significativos.

\begin{tabular}{|c|c|c|c|c|c|c|c|}
\hline & \multicolumn{2}{|c|}{ VERANO } & \multicolumn{2}{|c|}{ OTOÑO } & \multicolumn{2}{|c|}{ INVIERNO } \\
\hline & & Rad & $\downarrow \operatorname{Rad}$ & Rad & $\downarrow \operatorname{Rad}$ & $\uparrow \operatorname{Rad}$ & $\downarrow$ Rad \\
\hline & & 3-Aug & 1-Aug & 12-Oct & 14-Oct & 27-Jan & 29-Jan \\
\hline \multirow{2}{*}{$\begin{array}{c}\text { Radiación } \\
\text { día }\left(\mathrm{W} / \mathrm{m}^{2}\right)\end{array}$} & total & 446066 & 428794 & 229640 & 238338 & 172856 & 177955 \\
\hline & máxima & 912 & 1192 & 766 & 663 & 687 & 510 \\
\hline $\begin{array}{l}\text { Text a max } \\
\text { radiación }\end{array}$ & & 35,5 & 29,1 & 29,1 & 27,9 & 11,8 & 13,8 \\
\hline \multirow{2}{*}{$\begin{array}{l}\text { Tmax ext } \\
\text { promedio }\end{array}$} & REF & 39,0 & 36,9 & 38,4 & 37,9 & 28,5 & 32,1 \\
\hline & OPT & 44,9 & 41,9 & 45,0 & 44,0 & 28,3 & 32,9 \\
\hline \multirow{2}{*}{$\begin{array}{l}\text { Tmin ext } \\
\text { promedio }\end{array}$} & REF & 22,6 & 22,4 & 16,8 & 17,5 & 11,3 & 11,7 \\
\hline & OPT & 21,5 & 20,7 & 13,0 & 13,6 & 6,4 & 6,0 \\
\hline \multirow{2}{*}{$\begin{array}{l}\text { Tmax int } \\
\text { promedio }\end{array}$} & REF & 38,3 & 36,4 & 38,8 & 38,6 & 28,8 & 32,3 \\
\hline & OPT & 34,1 & 33,3 & 38,2 & 38,6 & 37,9 & 38,7 \\
\hline \multirow{2}{*}{$\begin{array}{l}\text { Tmin int } \\
\text { promedio }\end{array}$} & REF & 23,0 & 22,7 & 17,7 & 18,3 & 12,3 & 12,7 \\
\hline & OPT & 23,8 & 23,8 & 22,4 & 22,7 & 20,1 & 20,1 \\
\hline \multirow{2}{*}{$\Delta \operatorname{Tmax}$} & REF & 0,8 & 0,7 & 2,6 & 2,5 & 1,4 & 1,3 \\
\hline & OPT & 12,8 & 9,9 & 9,4 & 9,1 & 15,5 & 15,7 \\
\hline$\%$ AHORRO & $\begin{array}{l}\text { OPT- } \\
\text { REF }\end{array}$ & 18 & 15 & 18 & 17 & 27 & 22 \\
\hline
\end{tabular}

de Referencia (rojo), lo que refleja gran derroche de energía. En la ventana Optimizada en invierno tenemos un incremento de temperatura de en torno a $14^{\circ} \mathrm{C}$, en verano entre $10 \mathrm{y}$ $13{ }^{\circ} \mathrm{C}$, y en otoño entre 9 y $10^{\circ} \mathrm{C}$. En la ventana de Referencia en invierno tenemos un incremento de temperatura de en torno a $2{ }^{\circ} \mathrm{C}$, en verano en torno a $1{ }^{\circ} \mathrm{C}$, y en otoño de $3{ }^{\circ} \mathrm{C}$.

Estas diferencias se reflejan en los consumos de refrigeración y calefacción, la celda de la ventana de Referencia siempre registra un consumo superior a la celda de la ventana Optimizada (Figura 19). Las mayores diferencias se observan en el invierno, donde el porcentaje de ahorro relativo entre las dos celdas alcanza el $30 \%$.

En relación a los consumos totales de las dos celdas a continuación se muestran los consumos diarios de los meses de agosto (Figura 20), octubre (Figura 21), enero (Figura 22) y abril (Figura 23). De igual forma que en la anterior (Figura 19), a continuación, se observa que en términos generales siempre se registra un consumo mayor en la ventana de referencia, variando las diferencias en función de la época del año, lo mismo se corrobora a nivel anual observando el consumo total de cada mes (Figura 24).

Calculando el consumo acumulado anual de calefacción y refrigeración, obtenemos una reducción de consumo durante el año analizado de un 25,7\% (Figura 25).

máximo $\Delta \mathrm{T}$ int-ext



Figura 18. Incrementos de temperatura entre las dos caras del acristalamiento.

\section{Consumo (Wh)}

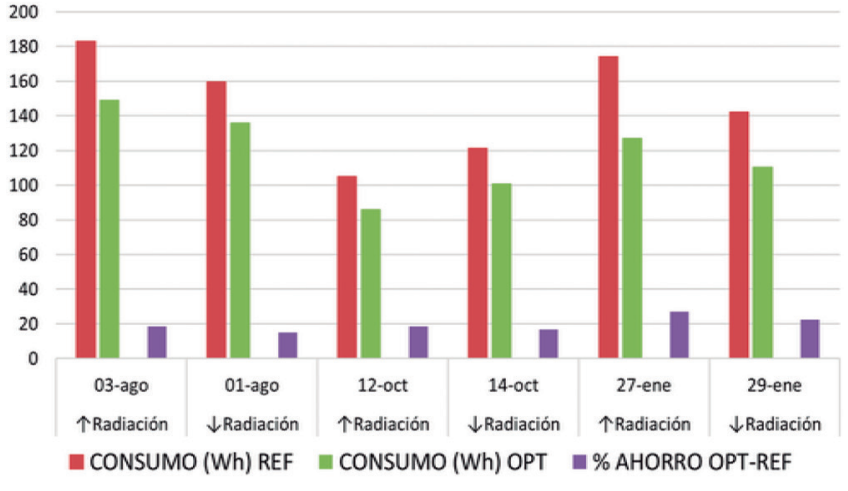

Figura 19. Consumo destinado a refrigeración y calefacción. 


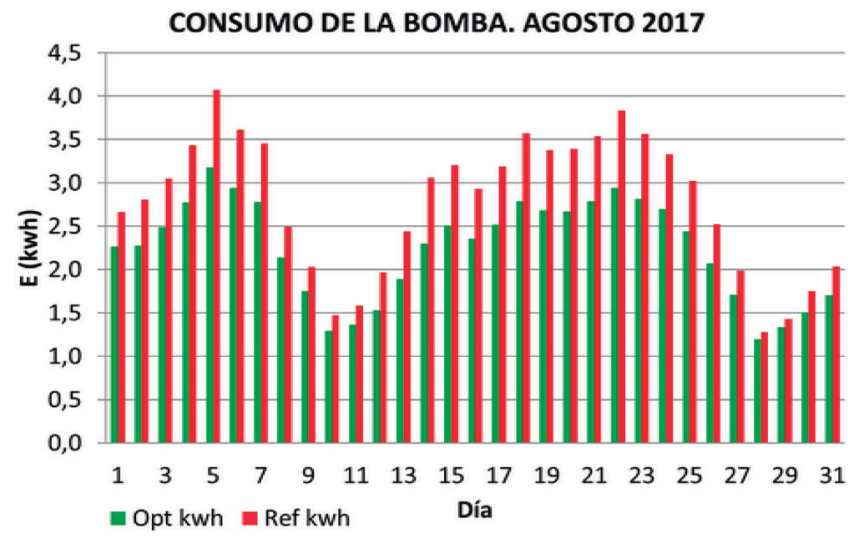

Figura 20. Consumos diarios destinados a climatización de agosto.

CONSUMO DE LA BOMBA. OCTUBRE 2017

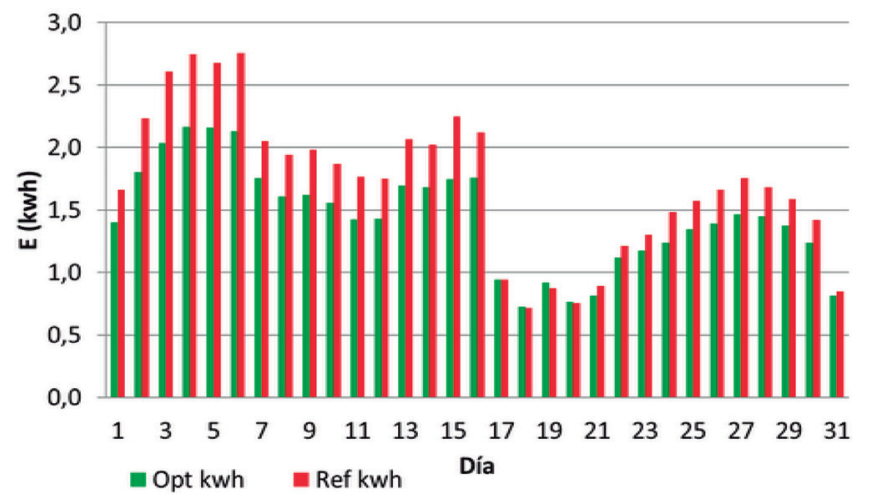

Figura 21. Consumos diarios destinados a climatización de octubre.



Figura 22. Consumos diarios destinados a climatización de enero.

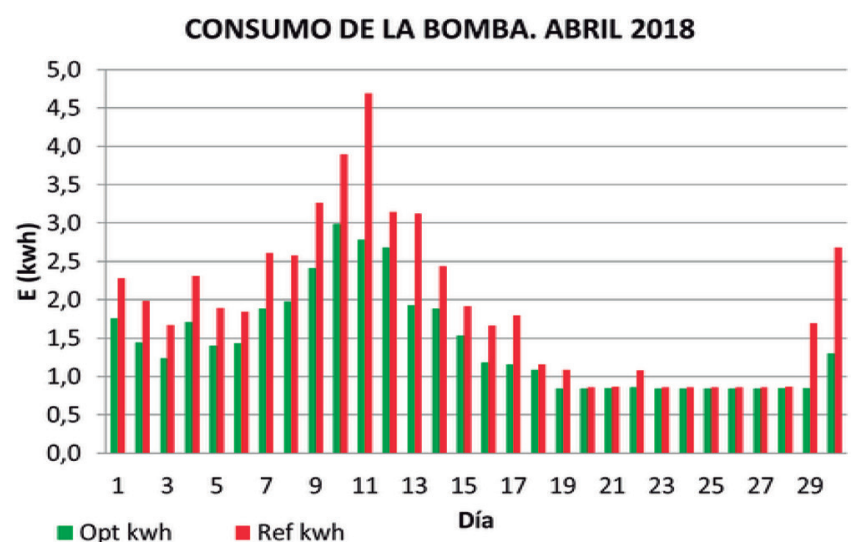

Figura 23. Consumos diarios destinados a climatización de abril.

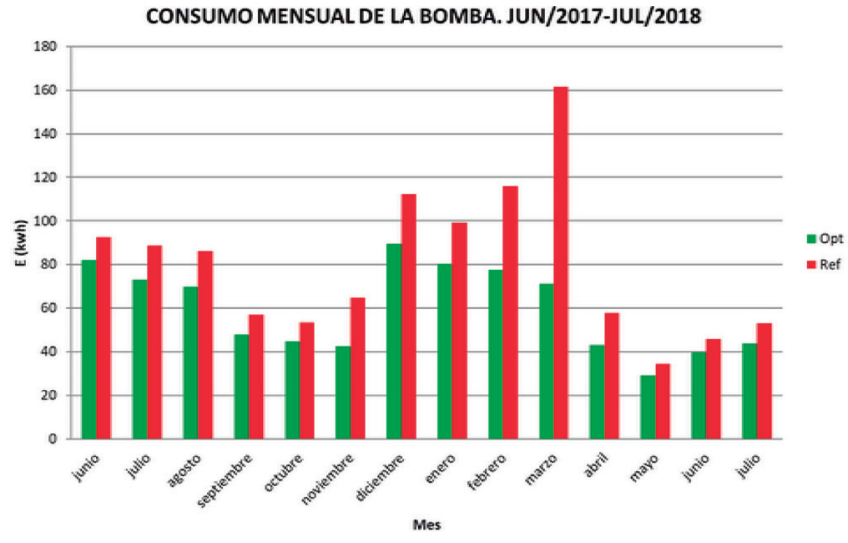

Figura 24. Consumos mensuales totales de cada mes.

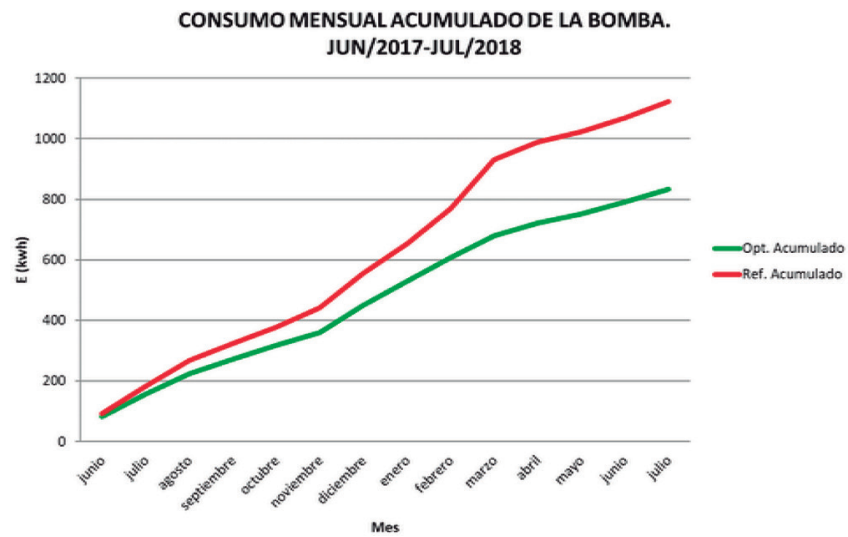

Figura 25. Consumo destinado a refrigeración.

\section{CONCLUSIONES}

El ensayo realizado el primer año ha concluido con éxito. Todos los sistemas activos: las bombas de calor, la apertura automática de la ventana de Referencia y el recuperador de calor de la ventana Optimizada han funcionado correctamente y su consumo ha sido registrado.

El sistema de monitorización ha tenido un funcionamiento óptimo. La aplicación diseñada para la visualización de datos resulta de gran utilidad para poder comprobar en remoto que el ensayo está marchando correctamente, para poder visualizar los datos en tiempo real y realizar un primer análisis general. También resulta especialmente útil como herramienta de comunicación y difusión

En relación al consumo de energía, hemos aislado el impacto de la ventana, cuantificando el ahorro en calefacción y refrigeración en las condiciones del ensayo en un $25,7 \%$ medio anual. En invierno la reducción del consumo es de un $36 \%$, en otoño de un $23 \%$ y en verano de un $17 \%$.

Los resultados obtenidos del análisis de la temperatura superficial de las dos ventanas confirman el efecto del aislamiento de la ventana Optimizada, lo que incide en que la temperatura de la cara interior del acristalamiento siempre está más próxima a la temperatura de confort, esto permite gran ahorro de energía.

En la ventana Optimizada en invierno tenemos un incremento de temperatura de en torno a $14{ }^{\circ} \mathrm{C}$, en verano entre 10 y $13{ }^{\circ} \mathrm{C}$, 
y en otoño entre 9 y $10^{\circ} \mathrm{C}$. En la ventana de Referencia en invierno tenemos un incremento de temperatura de en torno a $2{ }^{\circ} \mathrm{C}$, en verano en torno a $1^{\circ} \mathrm{C}$, y en otoño de $3{ }^{\circ} \mathrm{C}$.

Además, mantener la cara interior del acristalamiento próxima a la temperatura de confort evita transferencia de calor por radiación (tanto por superficie fría como caliente) evitando la falta de confort debida a la asimetría térmica.

El recuperador de calor introduce una carga adicional de renovación de aire que incide en un mayor consumo en calefacción y refrigeración. Por lo que si las condiciones de ventilación hubieran sido iguales en las dos ventanas se hubiera observado mayor reducción de consumo en la ventana optimizada. Sin embargo, hemos considerado necesario realizar este ensayo con recuperador de calor porque al aumentar la estanquidad de la envolvente será necesario siempre un aumento de la ventilación, el recuperador de calor garantiza una calidad de aire óptima.

Este ensayo es el primero realizado en el Laboratorio REVen, se continúa en la investigación con el análisis de otras variables como son el control solar, la ventilación natural, la calidad del aire y la calidad lumínica. Además, se da en el ámbito del proyecto REVen en el que también se ha monitorizado una vivienda y se han realizado simulaciones que complementarán este trabajo y serán objeto de futuras publicaciones.

\section{AGRADECIMIENTOS}

El Proyecto REVen: "Rehabilitación energética de viviendas sociales, aplicando productos innovadores de ventana con marcado CE" (BIA2014-56650-JIN) está financiado por el Estado de España (Ministerio de Economía, Industria y Competitividad) y la Comunidad Europea (fondos FEDER). Los autores desean agradecer a los patrocinadores industriales que han participado en el Proyecto. En la construcción del Laboratorio REVen: TAUJEL ha construido la totalidad del Laboratorio en taller e in situ, FINSA ha cedido $50 \%$ de los paneles de madera, GEOPANNEL ha cedido $50 \%$ del aislamiento de algodón reciclado, HECO $50 \%$ de los tornillos, PILOEDRE ha cedido $50 \%$ de la cimentación, DUPOND el $100 \%$ de la barrera de vapor, STORAENSO el $100 \%$ de la fachada ventilada y DANOSA EL 100\% de la impermeabilización, CARPINTEK y SIMATEC la ventana optimizada y las ventanas de la vivienda parte del Proyecto REVen y SAINT-GOBAIN todos los vidrios, ZEHNDER el recuperador de calor, SOMFY el motor, VAILLANT las bombas de calor, y GERLINGER-KLEBEBAND los materiales de sellado.

La construcción del laboratorio ha sido de elevado interés, permitiendo probar productos innovadores y experimentar con un sistema de paneles industrializado ligero de rápido montaje y altas prestaciones.

\section{REFERENCIAS}

(1) European Parliament, Council of the European Union (2018). Directive (UE) 2018/844 de 30 de mayo de 2018 por la que se modifica la Directiva 2010/31/UE relativa a la eficiencia energética de los edificios y la Directiva 2012/27/UE relativa a la eficiencia energética. Brussels, Belgium.

(2) European Parliament, Council of the European Union (2012). Directive 2012/27/EU of the European parliament and of the council of 25 October 2012 on energy efficiency, EC. (32012Lo027). Brussels, Belgium.

(3) Giuseppe, E. di, Iannaccone, M., Telloni, M., D’Orazio, M., Perna, C. di (2017). Probabilistic life cycle costing of existing buildings retrofit interventions towards nZE target: methodology and application example. Energy Build, 144: 416-432. https://doi.org/10.1016/j.enbuild.2017.03.055

(4) Spanish Government, IDAE (2014). Balance de energía final de año 2014. Ministerio de Energía, turismo y agenda digital. Recuperado de http://sieeweb.idae.es/consumofinal/bal.asp?txt=2014\&tipbal=t. Spanish Government.

(5) Asociación de Ciencias Ambientales (2012). Estudio sobre Pobreza Energética en España. Potencial generación de empleo derivado de la rehabilitación energética de viviendas. Proyecto REPEX.

(6) Santamouris, M. (2016). Innovating to zero the building sector in Europe: minimizing the energy consumption, eradication of the energy poverty and mitigating the local climate change. Solar Energy, 128: 61-94. https://doi.org/10.1016/j. solener.2016.01.021

(7) European Commission (2009). Directive 2009/72/EC of the European Parliament and of the Council of 13 July 2009 concerning common rules for the internal market in electricity and repealing Directive 2003/54/EC.

(8) European Commission (2009). Directive 2009/73/EC of the European Parliament and of the Council of 13 July 2009 concerning common rules for the internal market in natural gas and repealing Directive 2003/55/EC (Text with EEA relevance).

(9) Bluyssen P.M. (2009). The Indoor Environment Handbook: How to make buildings healthy and comfortable. London, UK: Earthscan.

(10) Boubekri M., Robert B., Hull L., Boyer L. (1991). Impact of windows size and sunlight penetration on office workers' mood and satisfaction: A novel way of assessing sunlight. Environment and Behavior, 23(4): 474-493. https://doi. org/10.1177/0013916591234004

(11) Leather, P., Pyrgas, M., Di Beale, Lawrence, C. (1998). Windows in the workplace: Sunlight, view, and occupational stress. Environment and Behaviour, 30(6): 739-762. doi:doi.org/10.1177/001391659803000601

(12) Wouters, P., Vandaele, L., Voit, P., Fisch, N. (1993). The use of outdoor test cells forthermal and solar building research within the PASSYS Project. Building and Environment, 28(2): 107-113. https://doi.org/10.1016/0360-1323(93)90044-4

(13) Strachan, P.A., Baker, P.H. (2008). Outdoor testing, analysis and modelling of building components. Building and Environment, 43(2): 127-128. https://doi.org/10.1016/j.buildenv.2006.10.008

(14) CSTB. (1990). The PASSYS Project. Subgroup Simplified Design Tool Final Report 1986-1989. EUR 12998 EN-o81-89PASSYS-SDT-FP-020. Commission of the European Communities Directorate-General XII for Science, Research and Development. 
(15) https://windows.lbl.gov

(16) Ruiz Valero, L., Ferreira, J., Gonzalez, V., Faxas, J. (2017). Diseño de células de experimentación para evaluar la eficiencia energética de sistemas constructivos de fachada. En XIV Congreso internacional de investigación científica.

(17) Alonso, C., Oteiza, I., García-Navarro, J., Martín Consuegra, F. (2016). Energy consumption to cool and heat experimental modules for the energy refurbishment of facades. Three case studies in Madrid. Energy and Buildings, 126: $252-262$. https://doi.org/10.1016/j.enbuild.2016.04.034

(18) León-Rodríguez, Á.L., Suárez, R., Bustamante, P., Campano, M.Á., and Moreno-Rangel, D. (2017). Design and Performance of Test Cells as an Energy Evaluation Model of Facades in a Mediterranean Building Area. Energies, $10(11): 1816$. https://doi.org/10.3390/en10111816

(19) Laboratorio de Ensayos Energéticos Para Componentes de la Edificación (LECE).

(20) Centro de Investigaciones Energéticas, Medioambientales y Tecnológicas (CIEMAT). Plataforma Solar de Almería (PSA). Recuperado de http://www.psa.es/es/index.php

(21) Gobierno Vasco. Laboratorio de Control de Calidad en la Edificación (LCCE). ENEDI (Energética en la Edificación). Recuperado de https://www.ehu.eus/es/web/enedi/eneditherm

(22) IEA ECBCS, Annex 43. Testing and Validation of Building Energy Simulation Tools. Recuperado de https://www.ieaebc.org/Data/publications/EBC_Annex_43_task34-Final_Mgmt_Report.pdf

(23) Blázquez, T., Suárez, R., Sendra, J.J. (2015). Towards a calibration of building energy models: A case study from the Spanish housing stock in the Mediterranean climate. Informes de la Construcción, 67(540): e128. https://doi.org/10.3989/ ic. 15.081

(24) Alonso, C. (2015). Rehabilitación energética de fachadas: Propuesta metodológica para la evaluación de soluciones innovadoras, basándose en el diagnóstico de viviendas sociales construidas entre 1940 y 1980 (Tesis Doctoral). Universidad Politécnica de Madrid. 